\title{
Comparative utility of disability progression measures in PPMS
}

\author{
Analysis of the PROMiSe data set \\ OPEN
}

Marcus W. Koch, MD, $\mathrm{PhD}$

Gary R. Cutter, PhD

Gavin Giovannoni, MD, $\mathrm{PhD}$

Bernard M.J. Uitdehaag, $\mathrm{MD}, \mathrm{PhD}$

Jerry S. Wolinsky, MD

Mat D. Davis, PhD

Joshua R. Steinerman, MD

Volker Knappertz, MD

Correspondence to

Dr. Koch:

abormes@hcg-int.com

Supplemental data at Neurology.org/nn

\section{ABSTRACT}

Objective: To assess the comparative utility of disability progression measures in primary progressive MS (PPMS) using the PROMiSe trial data set.

Methods: Data for patients randomized to placebo $(n=316)$ in the PROMiSe trial were included in this analysis. Disability was assessed using change in single (Expanded Disability Status Scale [EDSS], timed 25-foot walk [T25FW], and 9-hole peg test [9HPT]) and composite disability measures (EDSS/T25FW, EDSS/9HPT, and EDSS/T25FW/9HPT). Cumulative and cross-sectional unconfirmed disability progression (UDP) and confirmed disability progression (CDP; sustained for 3 months) rates were assessed at 12 and 24 months.

Results: CDP rates defined by $a \geq 20 \%$ increase in T25FW were higher than those defined by EDSS score at 12 and 24 months. CDP rates defined by T25FW or EDSS score were higher than those defined by 9HPT score. The 3-part composite measure was associated with more CDP events $(41.4 \%$ and $63.9 \%$ of patients at 12 and 24 months, respectively) than the 2 -part measure (EDSS/T25FW [38.5\% and 59.5\%, respectively]) and any single measure. Cumulative UDP and CDP rates were higher than cross-sectional rates.

Conclusions: The T25FW or composite measures of disability may be more sensitive to disability progression in patients with PPMS and should be considered as the primary endpoint for future studies of new therapies. CDP may be the preferred measure in classic randomized controlled trials in which cumulative disability progression rates are evaluated; UDP may be feasible for cross-sectional studies. Neurol Neuroimmunol Neuroinflamm 2017;4:e358; doi: 10.1212/ NXI.0000000000000358

\section{GLOSSARY}

9HPT = 9-hole peg test; CDP = confirmed disability progression; DMT = disease-modifying therapy; EDSS = Expanded Disability Status Scale; GA = glatiramer acetate; PPMS = primary progressive MS; T25FW = timed 25-foot walk; UDP = unconfirmed disability progression.

Patients with primary progressive MS (PPMS) represent $10 \%-15 \%$ of patients with MS and suffer the highest neurodegeneration-related disability. ${ }^{1-4}$ There are currently no approved treatments to ameliorate disease progression in PPMS, and there are several barriers to developing therapeutics in progressive MS. ${ }^{2,5}$ Specifically, individual disability measures may lack the sensitivity required to reveal all cases of disease progression within the defined time frame of a clinical trial. ${ }^{6}$

The Expanded Disability Status Scale (EDSS) remains the typical outcome measure in PPMS trials. However, it has been widely recognized as inadequate ${ }^{7}$ and is associated with several important weaknesses. ${ }^{3}$ Other widely used measures of disability in MS include the timed 25foot walk (T25FW) and the 9-hole peg test (9HPT). ${ }^{8,9}$ Recent studies have suggested that

\footnotetext{
From the Departments of Clinical Neurosciences and Community Health Sciences (M.W.K.), University of Calgary, Alberta, Canada; University of Alabama at Birmingham (G.R.C.); Barts and The London School of Medicine and Dentistry (G.G.), London, UK; Vrije Universiteit University Medical Center (B.M.J.U.), Amsterdam, The Netherlands; McGovern Medical School (J.S.W.), Department of Neurology, University of Texas Health Science Center at Houston; Teva Pharmaceutical Industries (M.D.D., J.R.S., V.K.), Frazer, PA; and Heinrich-Heine Universität Düsseldorf (V.K.), Germany.

Funding information and disclosures are provided at the end of the article. Go to Neurology.org/nn for full disclosure forms. The Article Processing Charge was funded by the authors.

This is an open access article distributed under the terms of the Creative Commons Attribution-NonCommercial-NoDerivatives License 4.0 (CC BY-NC-ND), which permits downloading and sharing the work provided it is properly cited. The work cannot be changed in any way or used commercially without permission from the journal.
} 


\begin{tabular}{|c|c|c|}
\hline \multirow{2}{*}{$\begin{array}{l}\text { Table } 1 \\
\text { Characteri }\end{array}$} & \multicolumn{2}{|c|}{$\begin{array}{l}\text { Baseline demographic and clinical } \\
\text { characteristics of patients who took } \\
\text { part in the PROMiSe trial and were } \\
\text { randomized to receive placebo }\end{array}$} \\
\hline & & Placebo cohort $(n=314)$ \\
\hline Male, $n$ (c & & $163(51.9)$ \\
\hline White, $n$ & & $284(90.5)$ \\
\hline \multicolumn{2}{|c|}{ Mean age, y (range) } & $50.2 \pm 8.1(23-66)$ \\
\hline \multicolumn{2}{|c|}{$\begin{array}{l}\text { Mean time from first } \\
\text { symptom, y (SD) }\end{array}$} & $10.7(7.7)$ \\
\hline \multicolumn{2}{|c|}{$\begin{array}{l}\text { Mean time from first } \\
\text { diagnosis, y (SD) }\end{array}$} & $5.1(5.5)$ \\
\hline \multicolumn{2}{|c|}{ Mean EDSS score (SD) } & 4.9 (1.2) \\
\hline \multicolumn{2}{|c|}{ Mean T25FW, s (SD) } & $11.2(10.5)$ \\
\hline \multicolumn{2}{|c|}{ Mean $9 H P T,{ }^{a} s$ (SD) } & 30.9 (19.6) \\
\hline
\end{tabular}

Abbreviations: 9HPT $=$ 9-hole peg test; EDSS = Expanded Disability Status Scale; T25FW = timed 25-foot walk.

${ }^{a}$ Average across 4 trials.

a combined disability measure that incorporates scoring from multiple instruments-for example, using T25FW, 9HPT, and EDSSmay be associated with more progression events among patients with PPMS, and thus higher reported event rates than achieved with any single instrument alone. ${ }^{9,10}$

The PROMiSe study represents one of the best and largest $(\mathrm{N}=943)$ data sources on patients with PPMS and offers a unique opportunity to assess the value of different functional measures of disability progression in a clinical trial setting. ${ }^{11}$ We report here

\begin{tabular}{|c|c|c|c|c|c|c|c|c|c|}
\hline \multirow[t]{4}{*}{ Table 2} & \multicolumn{9}{|c|}{$\begin{array}{l}\text { Cumulative and cross-sectional PROMiSe disease progression rates at } \\
12 \text { and } 24 \text { months }\end{array}$} \\
\hline & & \multicolumn{4}{|c|}{$\begin{array}{l}\text { Progression rates } \\
\text { at } 12 \text { months, \% }\end{array}$} & \multicolumn{4}{|c|}{$\begin{array}{l}\text { Progression rates } \\
\text { at } 24 \text { months, \% }\end{array}$} \\
\hline & & \multicolumn{2}{|c|}{ Cumulative } & \multicolumn{2}{|c|}{$\begin{array}{l}\text { Cross } \\
\text { sectional }\end{array}$} & \multicolumn{2}{|c|}{ Cumulative } & \multicolumn{2}{|c|}{$\begin{array}{l}\text { Cross } \\
\text { sectional }\end{array}$} \\
\hline & & UDP & 3M CDP & UDP & $3 M$ CDP & UDP & 3M CDP & UDP & 3M CDP \\
\hline EDSS alone & & 29.5 & 14.9 & 21.3 & 17.7 & 47.6 & 32.4 & 29.4 & 26.6 \\
\hline \multicolumn{2}{|c|}{ T25FW $20 \%$ alone } & 51.7 & 33.5 & 34.9 & 26.5 & 71.7 & 52.0 & 48.6 & 44.4 \\
\hline \multicolumn{2}{|c|}{ 9HPT $20 \%$ alone } & 26.6 & 8.4 & 15.4 & 9.6 & 38.0 & 18.0 & 19.6 & 15.4 \\
\hline \multicolumn{2}{|c|}{ EDSS or T25FW $20 \%$} & 58.1 & 38.5 & 42.3 & 32.7 & 77.9 & 59.5 & 53.7 & 49.5 \\
\hline \multicolumn{2}{|c|}{$\begin{array}{l}\text { T25FW } 20 \% \text { or } \\
\text { 9HPT } 20 \%\end{array}$} & 59.1 & 36.3 & 41.2 & 32.0 & 77.6 & 56.7 & 52.8 & 47.7 \\
\hline \multicolumn{2}{|c|}{$\begin{array}{l}\text { EDSS or T25FW } 20 \% \\
\text { or } 9 \text { HPT } 20 \%\end{array}$} & 63.8 & 41.4 & 47.8 & 37.5 & 82.1 & 63.9 & 57.5 & 52.8 \\
\hline
\end{tabular}

Abbreviations: 3M CDP = 3-month confirmed disability progression; 9HPT = 9-hole peg test; EDSS = Expanded Disability Status Scale; T25FW = timed 25-foot walk; UDP = unconfirmed disability progression.

For confirmed progression rates, patients who did not have the confirmation visit by the specified time point were censored for analysis purposes. the results of an analysis of the PROMiSe data set undertaken to better understand the utility of the different measures of disability progression-EDSS, T25FW, and 9HPT alone and in combinations - and to inform the design of future trials in PPMS.

METHODS Standard protocol approvals, registrations, and patient consents. Participating study sites in each individual country locally ensured all necessary regulatory approvals (e.g., institutional review boards/institutional ethics committees) in accordance with local regulations, including local data protection regulations used in the original collection of the data for this secondary data analysis.

Study design. The data set for this analysis was derived from the PROMiSe study, a randomized, double-blind, placebo-controlled clinical trial with a planned duration of 3 years. ${ }^{11}$ The design of the PROMiSe study has been reported previously. ${ }^{11}$ In summary, patients who took part in the PROMiSe study $(\mathrm{N}=943)$ were randomized in a 2:1 ratio to receive glatiramer acetate (GA) 20 $\mathrm{mg}$ once daily $(\mathrm{n}=627)$ or identical-appearing placebo $(\mathrm{n}=$ 316) by daily subcutaneous injection. ${ }^{11}$ The primary endpoint was time to confirmed disability progression (CDP), with CDP being defined as a change of $\geq 1$ point on the EDSS sustained for 3 months in patients with a baseline EDSS score of 3.0-5.0, or a change of $\geq 0.5$ points for 3 months in those with a baseline score of 5.5-6.5. ${ }^{11}$ Patients also completed the MS Functional Composite (MSFC) evaluation, a 3-part test including the T25FW and 9HPT and the Paced Auditory Serial Addition Test (PASAT). ${ }^{11}$

Patients. Patients eligible to participate in the PROMiSe study were aged between 30 and 65 years, with an EDSS score of 3.0-6.5, investigator-confirmed PPMS, and progressive symptoms including myelopathy for $\geq 6$ months before screening. Additional eligibility criteria included evidence of pyramidal damage on neurologic examination, including a pyramidal functional system score $\geq 2$, and evidence of multilevel CNS disease. ${ }^{11}$ Patients with any history of MS relapse, those with lymphopenia $<3,000$ cells $/ \mathrm{mL}$, and those who had used an interferon- $\beta$ drug, immunosuppressant, immunomodulating agent, corticosteroid, or investigational drug within 3 months of study initiation were not eligible to take part. ${ }^{11}$

Only data for patients randomized to placebo in the PROMiSe trial were included in this analysis in order to compare clinical measures in patients with PPMS for whom the natural course of the disease was not potentially affected by exposure to GA treatment.

Outcome evaluations. Disability was assessed using change in single (EDSS, T25FW, and 9HPT) and composite disability measures. Combination endpoints were defined as progression by EDSS or T25FW, 9HPT or T25FW, or by EDSS or T25FW or 9HPT. The PASAT was not included in this analysis of the PROMiSe database because of the potential for practice effects occurring from repeated administration. Moreover, the test may have limited measurement reliability, is sometimes difficult to administer, has been used less frequently in recent MS trials, and is not anticipated to be featured in future trials.

As per the PROMiSe study protocol, worsening of the EDSS was defined as a change from baseline of $\geq 1$ point (for baseline EDSS 3.0-5.0) or $\geq 0.5$ points (for baseline EDSS 5.5-6.5). ${ }^{11}$ 
Figure 1 Comparison of cumulative and cross-sectional UDP and CDP rates for EDSS, T25FW 20\%, and 9HPT 20\%

A

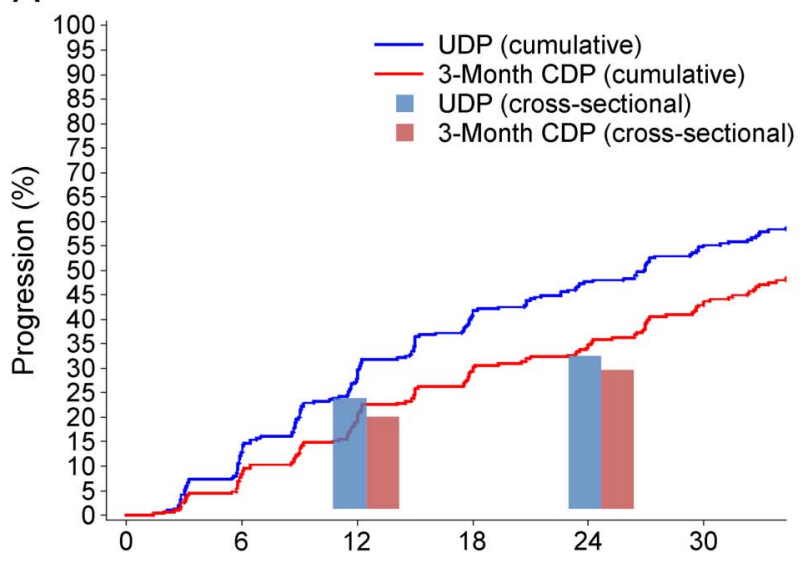

B

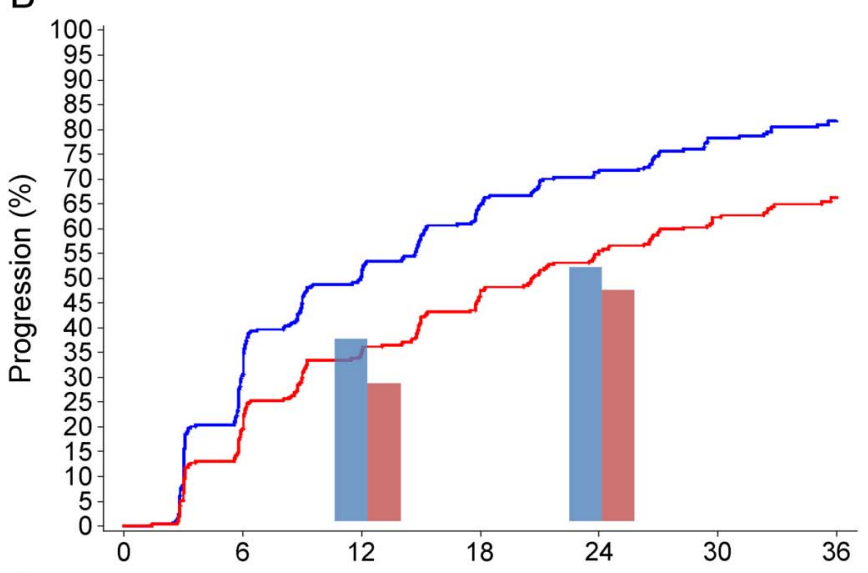

C

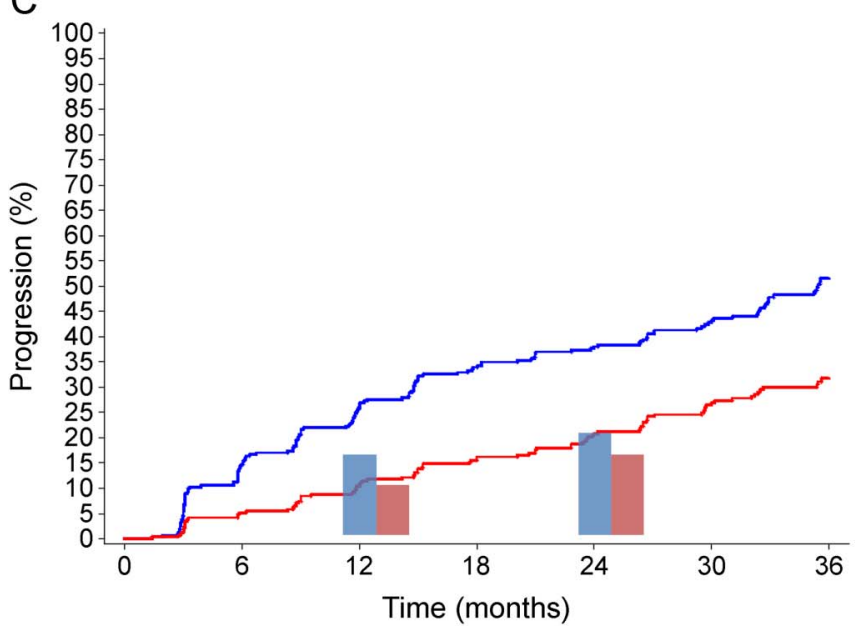

(A) EDSS rates. (B) T25FW $20 \%$ rates. (C) 9HPT 20\% rates. $3 \mathrm{M} \mathrm{CDP}=3$-month confirmed disability progression; 9HPT = 9-hole peg test; EDSS = Expanded Disability Status Scale; T25FW = timed 25-foot walk; UDP = unconfirmed disability progression.

Worsening of the $\mathrm{T} 25 \mathrm{FW}$ was defined as an increase of $\geq 20 \%$ compared with baseline or as the inability to complete the T25FW after baseline due to worsening disability (increase of EDSS to 7.0 or higher). ${ }^{12}$ Worsening of the 9HPT was defined as an increase of $\geq 20 \%$ compared with baseline (calculated as the average across 4 trials: 2 in the dominant hand and 2 in the nondominant hand) or as the inability to complete the 9HPT after baseline due to worsening disability. ${ }^{12}$ For each measure, rates of unconfirmed disability progression (UDP) and of 3month CDP were determined.

Two trial methodologies were evaluated: cumulative and cross-sectional. The cumulative approach describes the design of the PROMiSe trial and similar large-scale randomized clinical trials, with outcome measurement every 3 months and disability progression at any time point during follow-up contributing to an overall CDP proportion. The cross-sectional approach describes the design for simple, straightforward investigator-initiated trials such as futility trials ${ }^{13}$ and observational studies on PPMS disability progression. ${ }^{10}$ In this case, the measurement at one followup time point (e.g., 12 months) is compared with the baseline measurement. This analysis is restricted to patients in the PROMiSe trial receiving placebo in order to compare clinical measures in patients with PPMS for whom the natural course of the disease was not affected by exposure to GA treatment.

Statistical analyses. Cumulative progression rates were estimated using the Kaplan-Meier methodology. For summaries by month, 1 month was defined as 28 days. For confirmed disability events, patients who experienced a worsening event in the measure of interest that could not be confirmed due to the patient's discontinuation from the trial prior to the confirmation visit were censored at the time of the worsening. Other patients who did not experience the progression event were censored at their last day in the study. Cross-sectional progression rates were determined by comparing baseline and follow-up disability measures. Patients missing any of the 3 disability measures at baseline, the time point of interest, or the corresponding confirmation assessment were excluded from the analysis. The relative percentage contribution of each disability measure to disease progression rates observed for the combined EDSS or T25FW or 9HPT measure was derived by determining the number of individual patients progressing on 1,2 , or all 3 outcomes measures.

RESULTS A total of 316 patients were assigned to receive placebo in the PROMiSe study; 314 of these patients had a postbaseline EDSS assessment, and these patients constituted the population for the cumulative analyses presented here. Of these, $272 \mathrm{pa}-$ tients were included in the 12-month cross-sectional analysis, and 214 patients constitute the population for the 24-month cross-sectional analysis. Baseline demographic and clinical characteristics for the 314 patients who received placebo are shown in table $1 .{ }^{11}$ The baseline characteristics of the subgroup of patients assigned to receive placebo were consistent with those of the entire PROMiSe patient population. ${ }^{11}$

Table 2 shows cumulative and cross-sectional UDP and CDP rates at 12 and 24 months. Among single measures, a $\geq 20 \%$ worsening in T25FW (T25FW 20\%) was associated with the highest cumulative progression rates, followed by EDSS and then $a \geq 20 \%$ worsening in 9HPT (9HPT 20\%) at both the 12- and 24-month time points. Among combined measures, the composite of all 3 individual measures (i.e., EDSS or T25FW $20 \%$ or 9 HPT $20 \%$ ) had the highest cumulative 3-month CDP rate at both 12 and 24 months ( $41.4 \%$ and $63.9 \%$, respectively). Crosssectional 3-month CDP rates were also highest for the 
composite of all 3 scores than for any single or dual combination of scores at both 12 and 24 months (37.5\% and $57.5 \%$, respectively). UDP proportions were consistently higher than CDP proportions for all measures, with a considerably greater difference between UDP and CDP in the cumulative incidence of the composite of all 3 individual measures ( 1 year: $63.8 \%$ and $41.4 \%$, respectively; 2 years: $82.1 \%$ and $63.9 \%$, respectively) compared with the crosssectional proportions (1 year: $47.8 \%$ and $37.5 \%$, respectively; 2 years: $57.5 \%$ and $52.8 \%$, respectively).

The proportion of patients with UDP and 3month CDP for each of the disability metrics over the course of the study is shown in figure 1 for each study paradigm (cumulative and cross sectional). The T25FW 20\%-alone values were closely aligned with those from the combined EDSS-or-T25FW 20\% values at all time points over the course of the study (table 3).

The relative contribution of each of the individual component measures-together and in different combinations_-of a 3-part composite measure (EDSS or T25FW 20\% or 9HPT 20\%) is shown in figure 2 and figure e-1 at Neurology.org/nn. T25FW 20\% had the greatest contribution to the overall measure, followed by EDSS, and then 9HPT 20\%. These figures support the notion that CDP as defined by T25FW identifies individuals as progressors that the other measures would not have

\begin{tabular}{|c|c|c|c|c|c|c|c|c|}
\hline \multirow[b]{2}{*}{ Measure, \% patients } & \multicolumn{8}{|c|}{ Month } \\
\hline & 3 & 6 & 9 & 12 & 15 & 18 & 21 & 24 \\
\hline \multicolumn{9}{|l|}{$\begin{array}{l}\text { Unconfirmed disease } \\
\text { progression }\end{array}$} \\
\hline EDSS alone & 2.2 & 7.7 & 16.0 & 24.2 & 31.8 & 37.2 & 42.5 & 44.9 \\
\hline T25FW 20\% alone & 2.6 & 20.4 & 40.3 & 48.7 & 53.4 & 60.6 & 66.6 & 70.3 \\
\hline 9HPT $20 \%$ alone & 1.3 & 10.6 & 17.0 & 21.9 & 27.6 & 32.6 & 34.9 & 37.0 \\
\hline EDSS or T25FW $20 \%$ & 3.5 & 24.9 & 44.8 & 53.8 & 60.1 & 66.9 & 72.2 & 75.9 \\
\hline T25FW $20 \%$ or 9 HPT $20 \%$ & 3.5 & 26.8 & 46.4 & 54.2 & 61.1 & 67.7 & 73.3 & 77.0 \\
\hline $\begin{array}{l}\text { EDSS or T25FW } 20 \% \\
\text { or } 9 \text { HPT } 20 \%\end{array}$ & 4.1 & 30.9 & 50.5 & 58.9 & 66.1 & 72.6 & 77.8 & 81.2 \\
\hline \multicolumn{9}{|l|}{$\begin{array}{l}\text { 3-month confirmed disease } \\
\text { progression }\end{array}$} \\
\hline EDSS alone & 1.3 & 4.8 & 10.3 & 15.5 & 22.6 & 26.2 & 31.0 & 32.4 \\
\hline T25FW 20\% alone & 1.9 & 13.1 & 25.6 & 33.5 & 36.5 & 43.2 & 48.2 & 53.1 \\
\hline 9HPT $20 \%$ alone & 0.6 & 4.2 & 5.5 & 8.8 & 11.8 & 14.8 & 16.2 & 18.0 \\
\hline EDSS or T25FW $20 \%$ & 2.6 & 15.9 & 30.1 & 39.2 & 43.8 & 50.4 & 56.5 & 60.5 \\
\hline T25FW $20 \%$ or 9 HPT $20 \%$ & 2.2 & 15.0 & 27.5 & 36.6 & 41.6 & 48.6 & 53.0 & 57.8 \\
\hline $\begin{array}{l}\text { EDSS or T25FW } 20 \% \\
\text { or } 9 \text { HPT } 20 \%\end{array}$ & 2.9 & 17.9 & 32.0 & 42.4 & 48.6 & 55.5 & 60.9 & 64.9 \\
\hline
\end{tabular}

Abbreviations: 9HPT = 9-hole peg test; EDSS = Expanded Disability Status Scale; T25FW $=$ timed 25-foot walk. been identified. In other words, a greater proportion of patients identified as progressors by $\mathrm{T} 25 \mathrm{FW}$ were not identified as progressors by EDSS or 9HPT, as compared with the proportion of patients identified as progressors by EDSS who were not identified as progressors by $\mathrm{T} 25 \mathrm{FW}$ or $9 \mathrm{HPT}$ (figure e-2).

DISCUSSION The data presented here show that among patients with PPMS randomized to receive placebo in the PROMiSe study, T25FW 20\% at 12 and 24 months was associated with higher rates of disability progression than EDSS, and both T25FW $20 \%$ and EDSS were associated with higher disability rates than 9HPT 20\%. The 3-part combination measure (EDSS or T25FW $20 \%$ or 9 HPT $20 \%$ ) was associated with more 3-month CDP events (41.4\% and $63.9 \%$ of patients as 12 and 24 months, respectively) than the 2-part measure (EDSS or T25FW 20\% [38.5\% and 59.5\%, respectively]), and more progression events than any single measure (EDSS, $14.9 \%$ and 32.4\%, respectively; T25FW, $33.5 \%$ and $52.0 \%$, respectively; $9 \mathrm{HPT}, 8.4 \%$ and $18.0 \%$, respectively).

Minimal changes in the 9HPT 20\% outcome were noted over the course of the PROMiSe trial. As such, this measure may be less suitable than EDSS and T25FW 20\% when used alone; however, 9HPT may still have utility as part of a composite measure. Moreover, future studies should explore thresholds other than $20 \%$ worsening on performance measures such as 9HPT.

A marked difference was noted between cumulative and cross-sectional progression rates, which may inform the design of PPMS trials. Cumulative progression rates were generally higher than crosssectional rates, but more strikingly, there was a greater difference between unconfirmed and CDP using the cumulative approach. Based on our results, the normative approach to use CDP in classic randomized controlled trials is supported. Failure to confirm disability progression may have a neurobiological basis or may be due to measurement unreliability; it would be preferable to exclude these from pivotal trial analyses in both cases. For trials using the cross-sectional approach, measures of UDP may still be feasible. Such studies would be resource-sparing and less burdensome for participants, but would have acknowledged data sparsity and methodological limitations.

The observations presented here add to a growing body of evidence that suggests that combining specific disability measurements may be more useful in the clinical trial setting for assessing progression in patients with PPMS than single measures. ${ }^{9,10,14-16}$ In a retrospective database study of 181 patients with progressive MS (primary $47 \%$ of patients and secondary $53 \%$ of patients), combining change in $\mathrm{T} 25 \mathrm{FW}$ 
A

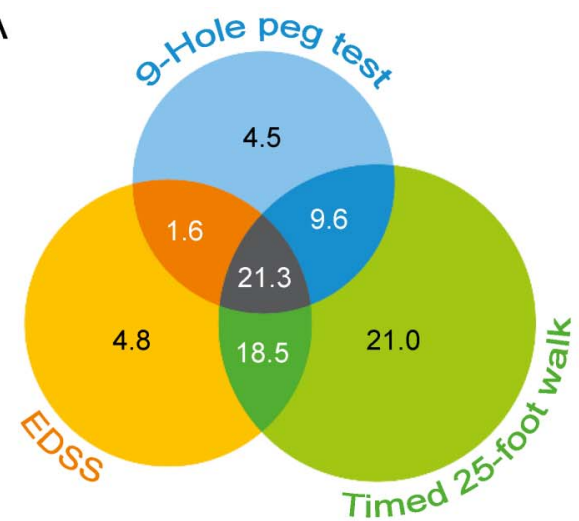

Did not progress: 18.8

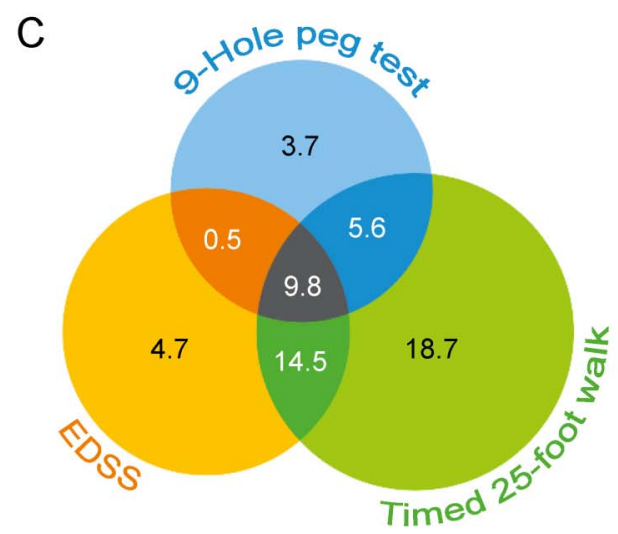

Did not progress: 42.5
B

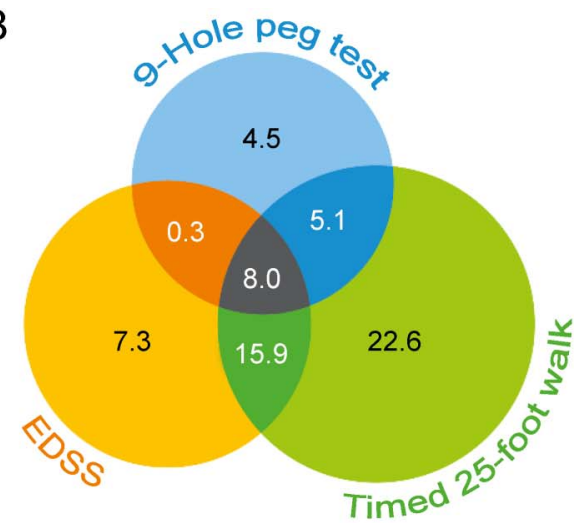

Did not progress: 36.3

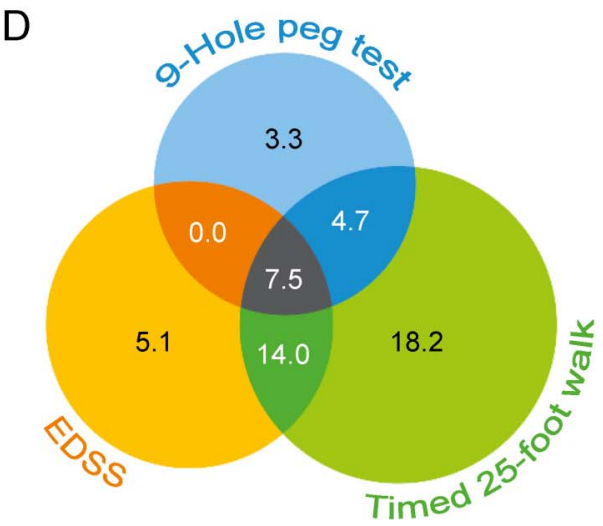

Did not progress: 47.2

(A) Cumulative UDP. (B) Cumulative 3-month CDP. (C) Cross-sectional UDP. (D) Cross-sectional 3-month CDP. 3M CDP = 3-month confirmed disability progression; 9HPT = 9-hole peg test; EDSS = Expanded Disability Status Scale; T25FW = timed 25-foot walk; UDP = unconfirmed disability progression.

with EDSS was significantly more predictive of patient prognosis than EDSS alone. ${ }^{15}$ An earlier retrospective database study of 161 patients with PPMS found that when comparing single measures or 2instrument combinations involving EDSS, T25FW, and $9 \mathrm{HPT}, \mathrm{T} 25 \mathrm{FW} / 9 \mathrm{HPT}$ predicted the greatest number of progression events after 1 year $(46 \%$ of patients progressed compared with $17 \%, 34 \%$, and $20 \%$ for the individual measures, respectively), and the combination of $\mathrm{T} 25 \mathrm{FW} / \mathrm{EDSS}$ predicted the greatest number of progression events after the second year $57 \%$ of patients progressed compared with $32 \%, 46 \%$, and $24 \%$ for the individual measures, respectively). ${ }^{11}$ An evaluation of data from the 96week Olympus (rituximab) trial ${ }^{17}$ in the 147 patients with PPMS randomized to placebo found that a combined measure consisting of EDSS/T25FW/9HPT was associated with more CDP events than did any single or dual combination measure. ${ }^{11}$ Progression rates at 96 weeks were $61.9 \%$ and $54.8 \%$ for those patients with an initial confirmed progression event at 12 and 24 weeks, respectively. ${ }^{9}$ Confirmed progression rates for EDSS alone were $38.5 \%$ and $30.4 \%$; for $\mathrm{T} 25 \mathrm{FW}$ alone the rates were $51.0 \%$ and $44.5 \%$; and for the 9HPT alone the rates were $21.1 \%$ and $17.4 \%$, respectively. ${ }^{9}$ Most recently, the large, prospective INFORMS (fingolimod) study, comprising patients with PPMS treated for at least 3 years, reported that a composite of EDSS, T25FW, or $9 \mathrm{HPT}$ predicted more progression events $(80.3 \%$ cumulative probability of CDP) than any of the individual components alone (EDSS 58.7\%, T25FW $70.0 \%$, and 9 HPT $41.3 \%$ of patients) among those randomized to placebo. ${ }^{14}$

Although those previous published studies offer similar conclusions to this study regarding the relative utility of outcome measures, they differ in several important ways that distinguish them from our analysis of the PROMiSe data set. The retrospective database study included both primary and secondary 
progressive patients with MS, was primarily focused on outcomes of early vs late changes on clinical scales, included patients who were exposed to diseasemodifying therapies (DMTs) during the course of the study, did not set a minimum disability criterion as per EDSS for study entry, and included lessfrequent patient assessment. ${ }^{15}$ Similarly, the earlier study likely included patients exposed to DMTs, while its entry criteria included an EDSS threshold score of 2.0-6.5, representing a less-disabled patient population than that of the PROMiSe study. ${ }^{10}$ The same EDSS criteria applied to the Olympus study, whereas none of these 3 studies, nor the INFORMS study, compared confirmed with unconfirmed progression or offered a cross-sectional analysis of disease progression data. ${ }^{9,14}$

Two other recently published studies address similar themes and arrive at compatible conclusions to those of this study. ${ }^{18,19}$ In one of these studies, however, the patient population consisted entirely of those with secondary progressive MS, ${ }^{18}$ whereas the other had a lower EDSS inclusion threshold (1-7), allowed inclusion of patients who had been treated with DMTs as recently as 3 months prior to study entry, and was intended as a validation study of a novel disability score (CombiWISE); that scoring measure, in addition to EDSS, T25FW, and 9HPT, also includes the Scripps Neurological Rating Scale. ${ }^{19}$ And, as with the previously noted studies, neither unconfirmed disease nor a crosssectional analysis was included in the design of these studies. ${ }^{18,19}$ Thus, this study offers several unique features that make it a potentially valuable contribution to the literature, such as reflecting the untreated natural history of PPMS by including only patients receiving placebo, including patients with more severe disability, comparing confirmed and unconfirmed disease progression, and including a cross-sectional analysis.

There is an unmet need for controlling disease progression in patients with PPMS. For these patients, individual measures of disease progression may limit the potential to assess the benefit of new agents to the extent that the composite measures have higher event rates. Based on the observations presented here and those from previous studies, future studies of agents for the treatment of PPMS may benefit from either using T25FW $20 \%$ as a single outcome measure or using T25FW 20\% in combination with the EDSS as a primary efficacy endpoint rather than EDSS alone, particularly if higher event rates over shorter exposure periods are sought. It is largely unknown whether specific disability outcomes would differentially detect treatment effects or whether this would differ according to the mechanism of the treatment under study.

\section{AUTHOR CONTRIBUTIONS}

Marcus W. Koch: conception of the study, data analysis, writing of the first draft, and revision of the manuscript. Gary R. Cutter: study/analysis review, manuscript review, and approval. Gavin Giovannoni: study/analysis design, manuscript review, and approval. Bernard M.J. Uitdehaag: study/analysis review, manuscript review, and approval. Jerry S. Wolinsky: overall conduct and image analysis of the original clinical trial, warehoused components of the trial data, early investigation of the database for clinical-biomarker correlations, evaluation plan and data review, and preparation of this manuscript. Mat D. Davis: study/analysis design, data analysis, manuscript preparation, review, and approval. Joshua R. Steinerman: study/analysis design, manuscript preparation, review, and approval. Volker Knappertz: study/analysis design, data analysis, manuscript preparation, review, and approval.

\section{ACKNOWLEDGMENT}

The authors thank the patients, investigators, and site personnel involved with the PROMiSe study. Dr. Justin Potuzak provided editorial support at the express direction of the authors. He had no role in the design or conceptualization of the study, in analysis or interpretation of the data, or in revising the manuscript for intellectual content.

\section{STUDY FUNDING}

This study was funded by Teva Pharmaceutical Industries.

\section{DISCLOSURE}

M.W. Koch served on the scientific advisory board for Roche and Biogen; received travel funding and/or speaker honoraria from Genzyme Sanofi and Biogen; and received research support from Teva and Alberta Innovated Health Solutions. G.R. Cutter served on the data and safety monitoring committees for AMO Pharmaceuticals, Apotek, Gilead, Horizon, Modigenetech/Prolor, Merck, Merck/Pfizer, OPKO Biologics, Sanofi-Aventis, Reata, Receptos/Celgene, Teva, NHLBI, and NICHD; received speaker honoraria from Consortium of MS Centers and Teva; served on the editorial board for Multiple Sclerosis, JASN, Alzheimer's \& Dementia: Translational Research \& Clinical Interventions; is president of Pythagoras; has consulted for Atara Biotherapeutics, Biogen GmbH, CereSpir Inc., Consortium of MS Centers, Genzyme, Genentech, Innate Therapeutics, Janssen, Klein-Buendel Incorporated, MedImmune, MedDay, Nivalis, Novartis, Opexa Therapeutics, Roche, Savara Inc., Somahlution, Teva, Transparency Life Sciences, and TG Therapeutics; participated in NARCOMS MS Patient Registry; and received research support from NIH/NAID, NIH/National Institute of Neurological Disorders and Stroke, NIH/NHLBI, NIH/NICHD, NIH/NIA, Consortium of MS Centers, US Department of Defense, NIH/NIAMS, NIH/ NIDDK, UAB/UCSD, Children's Hospital (Boston), the State of Alabama, and the Myasthenia Gravis Foundation. G. Giovannoni served on the scientific advisory board for Biogen Idec, Five Prime, Genzyme, GQ Pharma, Ironwood, Merck Serono, Novartis, Roche, Sanofi-Aventis, Synthon BV, Teva, Vertex, AbbVie, and Canbex; received speaker honoraria from Biogen Idec, Genzyme, GW Pharma, Merck Serono, Novartis, Roche, and Teva; is editor for Multiple Sclerosis and Related Disorders; consulted for Biogen Idec, Five Prime, Genzyme, GW Pharma, Ironwood, Merck Serono, Novartis, Roche, Sanofi-Aventis, Synthon BV, Teva, Vertex, AbbVie, and Canbex; served on the speakers' bureau for Novartis and Teva; and received research support from Genzyme and Merck. B.M.J. Uitdehaag consulted for Novartis, Merck Serono, Biogen Idec, Teva, Sanofi Genzyme, and Roche. JS Wolinsky served on the scientific advisory board for Clene Nanomedicine, Forward Pharma, MedDay, Novartis, Roche/Genentech, and Sanofi/Genzyme; received travel funding and/or speaker honoraria from ACTRIMS, Academic CME, CMSC, PRIME, WebMD, University of Kansas, University of Maryland, ECTRIMS, and ACTRIMS; served on the editorial board for Multiple Sclerosis Journal; was editor for Multiple Sclerosis and Related Disorders; has consulted for AbbVie, Acetylon, Alkermes, Bayer HealthCare, Celgene, Forward Pharma, EMD Serono, Genzyme, Novartis, Roche, Takeda, and Teva; received research support from NIH; and receives royalties for monoclonal antibodies out-licensed through the University of Texas Health Science Center at Houston to Millipore (Chemicon International) Corporation. M.D. Davis is employed by 
and holds stock or stock options in Teva Pharmaceutical Industries. J.R. Steinerman served on the data safety monitoring board for NIH; has been employed by Teva Pharmaceutical Industries; consulted for Click Therapeutics; and holds stock or stock options in Teva and Click Therapeutics. V. Knappertz is employed by Teva Pharmaceutical Industries and holds stock or stock options in Teva and Knopp Biosciences. Go to Neurology.org/nn for full disclosure forms.

Received January 3, 2017. Accepted in final form March 23, 2017.

\section{REFERENCES}

1. Stellmann JP, Neuhaus A, Lederer C, Daumer M, Heesen C. Validating predictors of disease progression in a large cohort of primary-progressive multiple sclerosis based on a systematic literature review. PLoS One 2014;9:e92761.

2. Koch MW, Cutter G, Stys PK, Yong VW, Metz LM. Treatment trials in progressive MS — current challenges and future directions. Nat Rev Neurol 2013;9:496-503.

3. Fox RJ, Thompson A, Baker D, et al. Setting a research agenda for progressive multiple sclerosis: the International Collaborative on Progressive MS. Mult Scler 2012;18: 1534-1540.

4. Holland NJ, Schneider DM, Rapp R, Kalb RC. Meeting the needs of people with primary progressive multiple sclerosis, their families, and the health-care community. Int J MS Care 2011;13:65-74.

5. Coetzee T, Zaratin P, Gleason TL. Overcoming barriers in progressive multiple sclerosis research. Lancet Neurol 2015;14:132-133.

6. Ziemssen T, Rauer S, Stadelmann C, et al. Evaluation of study and patient characteristics of clinical studies in primary progressive multiple sclerosis: a systematic review. PLoS One 2015;10:e0138243.

7. Ontaneda D, LaRocca N, Coetzee T, Rudick R; NMSS MSFC Task Force. Revisiting the multiple sclerosis functional composite: proceedings from the National Multiple Sclerosis Society (NMSS) Task Force on Clinical Disability Measures. Mult Scler 2012;18:1074-1080.

8. Bosma LV, Sonder JM, Kragt JJ, Polman CH, Uitdehaag BM. Detecting clinically-relevant changes in progressive multiple sclerosis. Mult Scler 2015;21:171-179.
9. Zhang J, Waubant E, Cutter G, Wolinsky J, Leppert D. Composite end points to assess delay of disability progression by MS treatments. Mult Scler 2014;20:1494-1501.

10. Bosma LV, Kragt JJ, Brieva L, et al. The search for responsive clinical endpoints in primary progressive multiple sclerosis. Mult Scler 2009;15:715-720.

11. Wolinsky JS, Narayana PA, O'Connor P, et al. Glatiramer acetate in primary progressive multiple sclerosis: results of a multinational, multicenter, double-blind, placebo-controlled trial. Ann Neurol 2007;61:14-24.

12. Schwid SR, Goodman AD, Apatoff BR, et al. Are quantitative functional measures more sensitive to worsening MS than traditional measures? Neurology 2000;55: 1901-1903.

13. Koch MW, Korngut L, Patry DG, et al. The promise of futility trials in neurological diseases. Nat Rev Neurol 2015;11:300-305.

14. Lublin F, Miller DH, Freedman MS, et al. Oral fingolimod in primary progressive multiple sclerosis (INFORMS): a phase 3, randomised, double-blind, placebo-controlled trial. Lancet 2016;387:1075-1084.

15. Bosma LV, Kragt JJ, Knol DL, Polman CH, Uitdehaag BM. Clinical scales in progressive MS: predicting longterm disability. Mult Scler 2012;18:345-350.

16. van Winsen LM, Kragt JJ, Hoogervorst EL, Polman $\mathrm{CH}$, Uitdehaag BM. Outcome measurement in multiple sclerosis: detection of clinically relevant improvement. Mult Scler 2010;16:604-610.

17. Hawker K, O'Connor P, Freedman MS, et al. Rituximab in patients with primary progressive multiple sclerosis: results of a randomized double-blind placebo-controlled multicenter trial. Ann Neurol 2009;66:460-471.

18. Cadavid D, Cohen JA, Freedman MS, et al. The EDSSPlus, an improved endpoint for disability progression in secondary progressive multiple sclerosis. Mult Scler 2017; 23:94-105.

19. Kosa P, Ghazali D, Tanigawa M, et al. Development of a sensitive outcome for economical drug screening for progressive multiple sclerosis treatment. Front Neurol 2016;7:131. 


\section{Neurology \\ Neuroimmunology \& Neuroinflammation}

Comparative utility of disability progression measures in PPMS: Analysis of the PROMiSe data set

Marcus W. Koch, Gary R. Cutter, Gavin Giovannoni, et al.

Neurol Neuroimmunol Neuroinflamm 2017;4;

DOI 10.1212/NXI.0000000000000358

This information is current as of May 10, 2017

Neurol Neuroimmunol Neuroinflamm is an official journal of the American Academy of Neurology.

Published since April 2014, it is an open-access, online-only, continuous publication journal. Copyright

Copyright $\odot 2017$ The Author(s). Published by Wolters Kluwer Health, Inc. on behalf of the American

Academy of Neurology. All rights reserved. Online ISSN: 2332-7812.

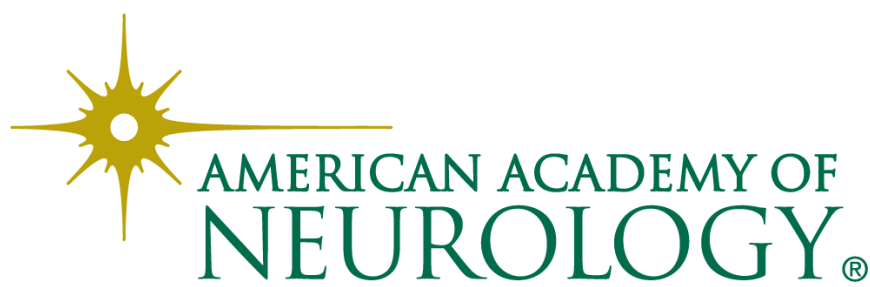




\section{Updated Information \& Services}

\section{Supplementary Material}

\section{References}

Citations

Subspecialty Collections

\section{Permissions \& Licensing}

\section{Reprints}

including high resolution figures, can be found at: http://nn.neurology.org/content/4/4/e358.full.html

Supplementary material can be found at: http://nn.neurology.org/content/suppl/2017/05/10/4.4.e358.DC1

This article cites 19 articles, 0 of which you can access for free at: http://nn.neurology.org/content/4/4/e358.full.html\#\#ref-list-1

This article has been cited by 1 HighWire-hosted articles: http://nn.neurology.org/content/4/4/e358.full.html\#\#otherarticles

This article, along with others on similar topics, appears in the following collection(s):

\section{All Clinical trials}

http://nn.neurology.org//cgi/collection/all_clinical_trials

Multiple sclerosis

http://nn.neurology.org//cgi/collection/multiple_sclerosis

Information about reproducing this article in parts (figures,tables) or in its entirety can be found online at:

http://nn.neurology.org/misc/about.xhtml\#permissions

Information about ordering reprints can be found online: http://nn.neurology.org/misc/addir.xhtml\#reprintsus

Neurol Neuroimmunol Neuroinflamm is an official journal of the American Academy of Neurology.

Published since April 2014, it is an open-access, online-only, continuous publication journal. Copyright

Copyright $\odot 2017$ The Author(s). Published by Wolters Kluwer Health, Inc. on behalf of the American Academy of Neurology. All rights reserved. Online ISSN: 2332-7812.

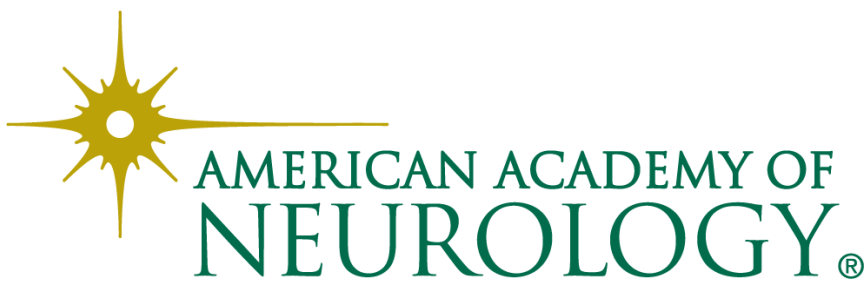

